applied, and renewed every few minutes, will soon give relief. The addition of some narcotic to the water may be useful. This, with rest to the eye, quiet of body, moderate abstinence, amply suffice for every case.

In all instances, the eye should not be rubbed and irritated. The sensation of something remaining often exists long after the extraction.

I suspect that the majority of metallic particles that get imbedded in the cornea are forced in by the common habit of rubbing the eye when anything enters.

No advantage would accrue from my enumerating the various substances in the mineral and vegetable kingdoms that may enter the eye.

The conjunctiva may be penetrated, and a particle of matter remain between it and the sclerotica. Encysting is likely to follow. I have seen several examples -I should say many-although I have never operated. The patients have either applied to me on account of something else, or I have met with them accidentally and spoken to them about the matter. Iron and copper have remained encysted for years.

The sclerotica itself is often penetrated, and retains bodies without much inconvenience. I have several times removed them when troublesome by snipping through the conjunctiva, raising it from itsattachment, and then accomplishing the desired end. Generally it has been metal that has entered, and forceps have been required for the extraction. I do not include in these remarks, injury to the eye from lime and other chemical agents.

The larvæ of insects are sometimes found beneath the eyelids; and this is not very astonishing when we remember that flies deposit their larvæ in different parts of animals. The occurrence has been noticed after a fly has accidentally entered the eye. It has occurred to drunken men asleep in fields. Several cases are on record of the successful removal of the worms. I know of one only in which the eyeball was damaged through perforations.

\section{DEATH WITH TETANIC SYMPTOMS: THE CORONER'S COUR'T.}

\section{By T. C. Leah, L.R.C.P.Ed., Hyde, near} Manchester.

Elizabeth Shaw, aged 14, the daughter of a beerhouse-keeper, a stout robust girl, previously in good health, was seized about 2 P.M. on Thursday, June 30th, with violent tetanic spasms, persistent in the trunk of the body-opisthotonos-but alternating with relaxation in the extremities. The slightest touch, as the act of examining the pulse, brought on a return of the spasms in the extremities, as if from an electric shock, and increased the trismus. The head was forcibly drawn back; the face flushed; the surface warm and moist; the pulse weak and irritable ; the muscles of the abdomen were much retracted; the feet incurvated; the intellect was unimpaired. There was no vomiting from the commencement of the symptoms to the time of death, which occurred before any remedial measures could be adopted, and under an hour from the first attack.

In reply to inquiries, the mother reported that the girl had not partaken of dinner, nor of food nor liquids since breakfast, so far as she knew; that she had not complained of illness, not taken any medicine; had received no wound nor bruise; had no cause for mental anxiety; that, in fact, she had been unusually cheerful during the morning, and had taken an active part in household duties and the family washing till the seizure. The catamenia, which commenced on the previous Saturday, had ceased on the evening before the seizure; and to this circumstance the girl had directed her mother's attention.

I declined to certify the cause of death, and advised the case to be reported to the coroner for the district. An inquisition, I understand, was held on the 2nd inst.- the day but one following the death. No medical evidence was taken; no post mortem examination was made; and a verdict of "Died in a fit" was returned.

The details of this case may possibly be interesting, as affording an illustration of the inefficient manner in which coroners' inquests in sudden and doubtful deaths are frequently conducted, and verdicts recorded, without the slightest medical evidence. A medical coroner would, I think, have considered a full and rigorous investigation imperative, with such characteristic symptoms present during life, conjoined with so rapidly fatal a termination.

[There can be no question that not holding an inquest in a case such as here described is quite inexcusable. The symptoms assuredly much more resenbled those of poisoning than of disease. EDIToR.]

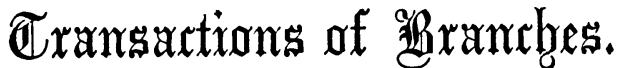

\section{BATH AND BRISTOL BRANCH.}

CASE OF DISEASED HUMERUS.

By Charles Steele, M.R.C.S., L.R.C.P.

[Rcad at Clifton, April 28th, 1364.]

THe patient, from whom the specimen now before you was taken, was seen by me for the first time in August 1863. The history of the case then given to me was as follows.

About eighteen months previously she felt aching pain, similar to that of rheumatism, in her right shoulder. In addition to this pain, there were soon perceived puffy swellings, between the metacarpal bones of the thumb and index finger, and of the index and middle fingers; these swellings used occasionally to appear, continue for a short time, and in a few hours subside. Aching pain from the hand to the elbow, and from the elbow to the shoulder, was also felt. These symptoms, occasional and slight at first, gradually increased in frequency and intensity. The suffering was noticed from first to last, to be most severe at one o'clock in the night. The following occurrence, which took place in November 1862, with its consequent alarming increase of symptoms (the pains having previously not been very much noticed or complained of) was the first to draw the serious attention of the patient and her friends to her state, and make them seek assistance beyond their own household remedies.

One day she perceived her son, who was near her, slip ; and, in order to prevent his falling down, suddenly extending her right arm, gave him a good push (bending back her fingers in doing so). She immediately felt as if she had struck first the elbow and then the shoulder, and as if the arm were broken. The same night she complained of great pain in the shoulder. After this she was never able to cut her own meat, or to raise a teapot or any such weight; but could for some time feed herself, and perform slight actions. The hand swelled much, and was obliged to be kept in a sling. The upper extremity also required to be kept warm, as increased pain was complained of on its becoming at all cool. At first, and for some long time, considerable relief was experienced from the application of hot water; this failing, ease 